\title{
Ensuring sustainable growth based on the artificial intelligence analysis and forecast of in- demand skills
}

\author{
Alena Vankevich*, and Iryna Kalinouskaya \\ Vitebsk State Technological University, Moskovsky Ave., 72, 210038 Vitebsk, Republic of Belarus
}

\begin{abstract}
Sustainable economic growth requires a system for forecasting the in-demand skills and competencies. The existing methods of analysis and forecasting of the labor market use truncated databases based on surveys of employers or registered vacancies on the state portal, which do provide reliable forecasts of the required competencies for the education system to ensure their timely formation. It is also impossible to analyze the need in terms of competencies, and not the number of employees. Therefore, a more reliable source of data is the analysis of vacancies and resumes collected by scraping from online job portals, which allows you to analyze vacancies and resumes in the context of the described competencies, and develop a forecast of their dynamics. The article presents an algorithm for using artificial intelligence in the analysis and forecasting of skills and competencies in demand, the advantages of which lie not only in the volume and speed of the processed information, but also in ensuring the quality and comparability of data.
\end{abstract}

\section{Introduction}

A key source of sustainable growth in modern conditions is the creation of highly productive jobs in new sectors of the economy, which objectively requires the formation of innovative skills and competencies. The Republic of Belarus is characterized by high literacy of the population (which testifies to the effectiveness of the secondary general education system), a high and growing share of employed people with academic and secondary specialized degrees. That is, formal signals suggest that the supply is highly qualified in the labor market. But the skills and competencies formed are not transformed into high labor productivity and high wages. GDP growth is ensured to a large extent by increasing the number of labor resources and work hours (that is, by expanding the supply of labor). High employment, low unemployment and a large number of work hours per year indicate that the Republic of Belarus has exhausted opportunities for sustainable growth due to an increase in labor supply. Therefore, a need arises in another source of growth,

\footnotetext{
* Corresponding author: vankevich_ev@,tut.by
} 
such as innovation, which implies acquiring new skills and competencies, that is, qualitative changes in the supply of labor.

The objective of the research is to develop new tools for analyzing and forecasting skills and competencies in demand on the labor market. The scientific hypothesis can be formulated as follows: the labor market and the market of educational services react to inaccurate signals about the shortage (excess) of specialties (qualifications). In reality, it is necessary to analyze and forecast not the number of required specialists, but the list of required skills, as they can be combined in different ways within one specialty of training and migrate from one specialty to another, making up a new combination of skills. The empirical basis is data on vacancies and CVs, obtained by scraping from the leading online job portals in Belarus.

\section{Current assessment of the demand for skills in the labor market and its shortcomings}

Currently, the analysis and forecast of in-demand personnel in the Republic of Belarus is carried out on the basis of the All-Republican Bank of Vacancies, where, in accordance with the Law "On employment of the population in the Republic of Belarus", all employers are required to provide data on vacancies within five days to. The database included 80.2 thousand vacancies as 15.09.2020. The second source of data for forecasting the demand for personnel is information from the labor, employment and social protection authorities on the number and structure of registered unemployed (the level of registered unemployment was $0.2 \%$ in 2019) [1, p. 20]. The third database is Goszakaz, the automated system on the need for personnel, which is filled in by employers (but the number of registered employers does not exceed 5\%). These data are used by the education system as signals in the formation of hiring control figures, which affects the systematic decrease in the volume of training in the field of higher education, the reduction of certain specialties and areas since, in accordance with them, the country has a stable shortage of workers and an excess of economic and legal specialists, with bias towards university education. But these are not representative databases, as they do not characterize the general problem (that is, there is a situation of "truncated" sample, on which decisions cannot be made). The use of other databases (for example, the results of the household employment survey) shows different situation on the labor market.

A higher level of education is a factor contributing to an increase in the level of employment and a decrease in individual risks of unemployment - the lowest level of unemployment is observed among the population with academic and secondary special degrees [2, P. 32, 87], therefore, a signal of a shortage of labor in the economy with a vocational education level is unreliable.

The study of the distribution of the employed population according to the qualifications of the work performed allows us to conclude about a steady deficit of skills and competencies in the labor market of the Republic of Belarus. Almost every third employed person performs work that does not correspond to his/her qualifications [2, P.36]. A significant share of workers has a qualification level corresponding but not related to the work performed $-17.4 \%$ (for individual vocational qualification groups - up to $27.4 \%$ ) [2, P.62], which is due to the emergence of new professions and an increase in the volume of professional self-development (retraining).

It is true that successful activity requires other skills and competencies, not the same and not in such a combination as they are formed by the education system. The Republic of Belarus has several times begun to study the analysis and forecast of the required competencies $[3 ; 4 ; 5]$. However, the lack of a sufficient empirical base hinders a largescale study of this problem. 
Individual research projects $[6 ; 7 ; 8]$ have obtained interesting results, but skills are not defined and analyzed in the datasets used. Employers, when submitting information about vacancies, independently determine the skills. Professional standards could help them in this, but they are just beginning to be developed in the Republic of Belarus. Therefore, a need arises to deeper understand the skills demanded by the labor market and the ways of their formation for the formation of appropriate policies in the field of education and employment, and not only to justify the target figures for admission to educational institutions. This cannot be determined from traditional data sources (administrative and statistical). New sources of data are needed that can be obtained from online job portals. Each of the online job portals covers from $0.2 \%$ to $2.5 \%$ of the demand for labor (assessed by the number of employees), while enterprises are quite actively involved in posting their vacancies on online platforms - from 50 to $95 \%$ of enterprises post their jobs there. vacancies [9]. Comparison of the most popular vacancies from the three largest online portals in Belarus shows that these resources characterize different segments of the labor market [9].

\section{Theoretical approaches to determining the skills in demand}

Theoretical approaches to the analysis and forecasting of skills and competencies in demand in the labor market are sufficiently differentiated in terms of the initial research methodology, a set of indicators for assessing the problem, and the empirical basis used for testing.

There are several approaches to the formation of the empirical base for identifying the skills in short (or the skills most in demand): interviews with employers [10]; data on the number of vacancies (jobs) declared by organizations to the state employment service bodies or other databases (portals, recruiting agencies, mass media); administrative and statistical data $[6 ; 11]$; using big data $[12 ; 13 ; 14 ; 15 ; 16]$. The achieved theoretical results led to the use of the relevant indicators in qualifying the specialists in demand (the level of employment, the level of unemployment, professional qualification groups, levels of education, and types of economic activity). However, the listed approaches are focused on the number of specialists and the number of vacancies in certain professions and areas of training, and neglect specific skills and competencies. In the modern context, the functional flexibility of the workforce is increasing, that is, an employee masters several specialties, supplementing them with individual competencies and skills, bypassing the formal education system. Thus, the need for skills and workers are significantly different in volume and structure, and the supply of labor is different if measured in terms of the number of labor force or the number of skills and competencies available. That is, the main thing in the analysis and forecast of both the demand for labor and its supply is not diplomas, but skills. The review of skills (competencies) set out in job descriptions provides more accurate insight into the analysis and forecasting of labor demand. Therefore, research tools must be used that help to establish the need for new skills (rather than for professions), the combination of which forms new professions.

The economic literature has just started studying this issue and has already faced the following difficulties:

- lack of single approach to describing skills and competencies due to the use of different classifiers or even free description of skills,

- lack of unified database of vacancies and applicants (or CVs) with a description of skills and competencies.

The listed circumstances make it necessary to use Big Data technology to analyze the correspondence between the required and available skills. Detailed information on the evaluation of online portals can be obtained from primary information about vacancies 
obtained from their sites by scraping, or from the portal of the state employment service through the API [15, p.20]. Scraping data has proven itself well in forming a database and testing any hypothesis on it $[12 ; 13 ; 15]$. As an example, vacancies and CVs were collected by scraping from the largest online job portals in Belarus - both state (GSZ.gov.by) and private (Belmeta.com, Jobs.tut.by) (Table 1), which made it possible to isolate and compare the most in-demand competencies in vacancies and the most represented competencies in the CVs of applicants.

Table 1. Number of downloaded vacancies, (July - August 2020)

\begin{tabular}{|l|c|c|c|}
\hline & Jobs.tut.by & Belmeta.com & Gsz.gov.by \\
\hline $\begin{array}{l}\text { Number of vacancies collected by } \\
\text { scraping from the portal, thousands }\end{array}$ & 5.9 & 22.8 & 24.7 \\
\hline $\begin{array}{l}\text { Share of downloaded vacancies in the } \\
\text { total number of vacancies on the portal, } \\
\%\end{array}$ & $25.05 \%$ & $32.5 \%$ & $31.46 \%$ \\
\hline
\end{tabular}

A review of the list of competencies shows that, in fact, the same competencies are described in different ways, so they can be grouped: 50 of the listed competencies are grouped into 12, and then the ranking of in-demand competencies looks different (Table 2). Jobs.tut.by is the largest portal in terms of the CVs posted - more than 2.2 million CVs are registered, which is $44.3 \%$ of the labor force in the Republic of Belarus (that is, it covers the labor supply in the country to the greatest extent). Therefore, the structure of and changes in the CVs posted have relevance for their study. With the help of a scraper program, 423 thousand CVs were downloaded from jobs.tut.by for 2015-2019, the analysis of which shows seasonal pattern in the submission of resumes, and the average age of applicants (mainly 25-40 years). The description of the existing skills and competencies in the CVs is quite arbitrary, as in the case of vacancies, therefore the grouping of the TOP-50 competencies into 15 groups allows presenting the profile of applicants in a slightly different way.

Comparison of the most in-demand competencies (grouped from the TOP-50 competencies from vacancies) with the most represented competencies among applicants (grouped from the TOP-50 competencies from the CVs) allows us to conclude that:

- the most demanded among employers are the following competencies: "active sales", "PC user (various programs)", "negotiating, business communication", "teamwork" and personal business competencies,

- the following competencies are most common to the CVs: "PC user, various programs", "teamwork", "negotiation", "active sales" and personal business competencies,

- the conjuncture of the labor market, measured through the number of competencies in the resume per 1 competence in the vacancy was: active sales - 18.3; PC user, various programs - 62; negotiation, business communication - 27.7; teamwork - 37.9; the English language - 8.9 .

Comparison of the most in-demand competencies presented in vacancies and the most offered competencies presented in applicants' CVs reveals a gap between the two of them: job seekers offer the most IT skills, while employers look for a different combination of skills. Formation of the program and training of artificial intelligence in the skills of classification of competencies described in vacancies and in resumes, and their comparison in the context of professions, regions, types of economic activity will increase the validity of measures in the development of employment policy and education policy, as well as decisions made by individuals. 


\section{Algorithm of the artificial intelligence in the analysis and forecast of in-demand skills and competencies}

Online platforms as data sources have several advantages over administrative databases, namely cost and the ability to form different target samples. Scraping data on vacancies from portals provides a lot of interesting information for analysis, however, its main drawback is the problem of representativeness and quality of data $[16 ; 17 ; 18]$. Therefore, to overcome these limitations, a methodological approach was developed for processing and analyzing data collected by scraping from online job portals using artificial intelligence, which involves the use of artificial intelligence to group professions and skills according to uniform classifiers to identify new skills that are most/least in demand. and most/least represented in the CVs, establishing the degree of correspondence (or imbalances) between them.

Algorithm of the artificial intelligence in the analysis and forecast of in-demand skills and competencies includes the following steps:

1. Retrieval of CVs and vacancies from job search sites and other web sources;

2. Processing of text data retrieved from $\mathrm{CVs}$ and vacancies (cleaning and bringing to a single form);

3. Deduplication of data;

4. Retrieval and classification of positions from CVs and vacancies according to the National Classifier of the Republic of Belarus OKRB 014-2017 "Occupations" (to obtain a database structured according to a single classifier);

5. Retrieval and classification of competencies from CVs and vacancies by ESCO - to ensure the possibility of comparison;

6. Presentation of data from CVs and vacancies using analytical systems (Superset and Neo4j). The Superset analytical system provides analysis of large amounts of data and visualization of the results obtained. Neo4j is a graph database management system that provides visualization of the relationship of research objects in the form of a graph. Thus, when analyzing the labor market, positions and competencies can act as the vertices of the graph, and the characteristics of connections (reference, materiality, generalization) can act as edges;

7. Development of training programs based on identified labor market imbalances, forecasting of new professions.

As an example, we analyzed 117 unique competencies identified in 89 active CVs and 33 vacancies for Business Analyst.

Table 2 presents a summary of the analysis of the identified Business Analyst competencies, which showed significant discrepancies between the skills, competencies, and knowledge required in vacancies and those available for Business Analyst candidates.

Table 2. Comparison of Business Analyst competencies obtained from job descriptions and CVs

\begin{tabular}{|c|c|c|c|c|}
\hline \multirow{2}{*}{ Type } & \multirow{2}{*}{ Group } & \multirow{2}{*}{ Competence } & \multicolumn{2}{|c|}{ Competence indicated, \% } \\
\hline & & & $\mathrm{CV}$ & vacancies \\
\hline \multirow{6}{*}{ 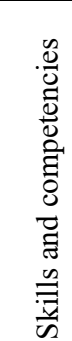 } & \multirow{2}{*}{$\begin{array}{l}\text { S1. Communication, co- } \\
\text { operation, and creativity }\end{array}$} & Teamwork & 22.0 & 13.3 \\
\hline & & $\begin{array}{l}\text { Creativity and creative } \\
\text { thinking }\end{array}$ & 11.0 & 6.5 \\
\hline & \multirow{4}{*}{ S5. Computer use } & $\begin{array}{l}\text { Analysis of large amounts of } \\
\text { information }\end{array}$ & 16.6 & 6.7 \\
\hline & & Computer use & 22.3 & 20.0 \\
\hline & & Work in office programs & 11.1 & 6.9 \\
\hline & & Microsoft Visio & N/A & 26.7 \\
\hline
\end{tabular}


Table 2. Continued

\begin{tabular}{|c|c|c|c|c|}
\hline \multirow{8}{*}{ 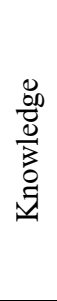 } & \multirow{8}{*}{$\begin{array}{c}\text { Business, administration, } \\
\text { and law }\end{array}$} & Business analysis & 5.6 & 46.7 \\
\hline & & Business process modeling & 5.0 & 46.5 \\
\hline & & Business process optimization & 5.4 & 33.3 \\
\hline & & Business metrics analysis & N/A & 13.3 \\
\hline & & Business plan analysis & 5.2 & 26.7 \\
\hline & & Business process analysis & 5.1 & 26.3 \\
\hline & & Business requirements analysis & 5.4 & 13.0 \\
\hline & & Business process reengineering & $\mathrm{N} / \mathrm{A}$ & 26.3 \\
\hline
\end{tabular}

The analysis of competencies showed that Business Analyst candidates consider essential such sills as communication, creative and digital skills and competencies, as well as knowledge of business, administration, law, and information technology. The presence of these competencies in the CVs varies from $11.0 \%$ to $22.3 \%$. The results of the analysis of the competencies indicated in vacancies found that the computer skills and knowledge of business, administration and law are essential for employers. Availability of these competencies in vacancies varies from $13.0 \%$ to $46.7 \%$. A comparative analysis of competencies from the CVs and vacancies showed that the required essential skills of using graphic editors, knowledge of analyzing business indicators and reengineering business processes are completely absent from Business Analyst candidates. While knowledge of business analysis, modeling and optimization of business processes, analysis of plans, processes, business requirements, which is essential for employers, are optional in candidates' CVs. Thus, further training of artificial intelligence in the classification of skills and competencies and their comparison will make it possible to develop a forecast of the demand for labor and its supply at a qualitatively different level.

\section{Conclusion}

1. Sustainable growth requires forecasting the need for new skills and competencies to ensure timely training of specialists.

2. The currently used methods of forecasting the need for personnel are based on formal signals (the availability of a diploma) and truncated empirical databases that do not identify the skills and competencies in demand and compare them with those presented on the labor market.

3. To address the problem, it is advisable to use data from online job portals collected by scraping or API, for the analysis of which a methodological approach has been developed for applying artificial intelligence for the correct classification and comparison of skills and competencies contained in vacancies and CVs (according to uniform classifiers).

4. The artificial intelligence-based grouping of competencies according to uniform classifiers (OKRB "Occupations" or ESCO) allows analyzing the correspondence between the demand for skills (presented in vacancies) and their supply (presented in CVs), as well as identifying the pool of skills not indicated in CVs but in demand in the labor market.

5. The obtained results would be useful for educational institutions to adjust curricula and form skills in demand, for governing bodies to forecast the labor market, and for the population. 


\section{Acknowledgment}

The study was conducted by the author in the framework of the assignment "Development of theoretical and methodological approaches and applied tools for human resource management in a modern organization" of the State program of scientific research of the Republic of Belarus "Economics and humanitarian development of the Belarusian society

\section{References}

1. Labor and employment in the Republic of Belarus, Minsk, National Statistical Committee of the Republic of Belarus (2020)

2. Statistical Bulletin, 146 (2020)

3. Youth unemployment in frontier regions: the experience of comparative analysis, 157 (2017)

4. N.V. Makovskaia, Transformation of labor processes in the course of modernization of enterprises, 144 (2015)

5. S.A. Kasperovich, Problems of forecasting and state regulation of socio-economic development: materials of the XVII Intern. scientific. conf., 1, 89 (2016)

6. E.Ia. Varshavskaia, E.S. Katyrlo, Education Issues, 2, 98 (2019)

7. E.V. Vankevich, E. Kastel-Branko, Belarusian economic journal, 2(79), 73 (2017)

8. S.D. Belov, J.N. Javadzade, I.S. Kadochnikov, V.V. Korenkov, P.V. Zrelov, Proceedings of the 27th International Symposium Nuclear Electronics and Computing (NEC'2019) Budva, Becici, Montenegro, September 30 - October 4, 469 (2019)

9. E.V. Vankevich, O.V. Zaitseva, Digital transformation, 2(11), 33 (2020)

10. Ben Kriechel, Tomas Rasovec, Rob Wilson, Guide to anticipating and matching skills and jobs, 2, Part B (2016)

11. S.Iu. Roshchin, S.A. Solntsev, Russian Management Journal, 15(2), 173

12. N. Dawson, M.-A. Rizoiu, M.-A. Williams, B. Johnston, Predicting Skill Shortages in Labor Markets: A Machine Learning Approach

13. Towards a reskilling Revolution. Future of Jobs for All, World Economic Forum (2018)

14. Ph. Brown, M. Souto-Otero, Journal of Education Policy (2018)

15. M. Mezzanzanica, F. Mercorio, Intelligence Systems, A Brief Introductory Guide, ETF (2019), https://www.etf.europa.eu/

16. L.M. Kureková, M. Beblavý, A. Thum-Thysen, IZA J Labor Econ, 4, 18 (2015)

17. Jobs of Tomorrow, Mapping Opportunity in the New Economy, World Economic Forum (2020)

18. D. Jeske, T. Calvard, Employee Relations, 42(1), 248 (2020) 